\title{
Impact of Iron and Vitamin B12 Anaemia at Glycosylated Hemoglobin Level: A Case Control Study
}

\author{
${ }^{1}$ Dr VD Maheshwari, ${ }^{2}$ Dr. Shekhar Capoor, ${ }^{3}$ Dr. Surbhi Chaturvedi, \\ ${ }^{4}$ Dr. Ankit Manglunia, ${ }^{5}$ Dr. Ankush Singla \\ Mahatma Gandhi Medical College and Hospital, Sitapura, Jaipur
}

\begin{abstract}
Introduction: Diabetes Mellitus (DM) refers to a group of common metabolic disorder. It is a complex, chronic illness requiring continuous medical care with multifactorial risk reduction strategies beyond glycemic control. $\mathrm{HbA}_{\text {Ic }}$ which was primarily used as a test of glycemic control has now been added as a diagnostic test. One condition that effect erythrocyte turnover is anemia. Iron and Vitamin B12 deficiency inhibit erythropoiesis and increase the mean survival duration of erythrocyte, leading to increase $\mathrm{HbA}_{\mathrm{lc}}$.

Methods: The study was conducted in tertiary care hospital, Jaipur. The study involved 60patients out of which 30 were of Iron deficiency anemia and remaining 30 had Vitamin B 12 deficiency anemia. Permission was taken from the ethical committee before starting the study. A well informed written consent was taken prior to the study and the results of the same were compared with 30 non anemic, non diabetic controls using ANOVA and T test analysis.

Results: Out of 30 participants in each group, $36.67 \%$ were male and $63.335 \%$ were female in iron deficiency group, $53.33 \%$ were male and $46.67 \%$ were female in vitamin B12 deficiency group, $60 \%$ were male and $40 \%$ were female in control group.In Iron deficiency anemia 10 out of 30 participants (33.33\%) had Hba $\mathrm{Hc}_{\text {ic }}$ the range of impaired glucose homeostasis(5.6 -6.5) and in Vitamin B12 deficiency anemia 12 out of 30 participants (40\%) had $\mathrm{Hba}_{1 \mathrm{c}}$ in the range of impaired glucose homeostasis. Interestingly 2 patients from irondeficiency anemia had $\mathrm{Hba}_{1 c}$ in diabetic range (more then 6.5). Our study reported significant negative trend when Hemoglobin was compared with $\mathrm{HbA}_{\text {Ic }}$ in patients with iron deficiency anemia, that is, patients with lower Hemoglobin had higher $\mathrm{HbA}_{1 \mathrm{c}}$.

Conclusion: Anemia and Diabetes are a common problem in Indian scenario and use of HbA $A_{l c}$ to diagnose prediabetes and diabetes in iron-deficient populations may lead to a spuriously exaggerated prevalence of prediabetes.
\end{abstract}

\section{Introduction}

Diabetes Mellitus refers to the group of common metabolic disorders that share the phenotype of hyperglycemia with an increasing incidence worldwide ${ }^{1}$. Diabetes Mellitus will be a leading cause of morbidity and mortality. The prevalence of Diabetes Mellitus is rising rapidly in India presumably because of increase obesity, decrease activity levels and industrialization. HbAlc which was primary used to test glycemic control has now been added as a diagnostic tool, therefore it is more important today than earlier ${ }^{2}$. HbA1c levels are not affected by blood sugar levels alone. Any condition that shortens the life span of erythrocytes is likely to decrease the HbA1c level. Iron and Vitamin B12 deficiency, renal failure and bone marrow suppression in alcoholism inhibit erythropoiesis and increase the mean survival of erythrocytes, leading to increase in HbA1c level.However, hemolytic anemia, chronic liver disease, and increased hemolysis from splenomegaly increase reticuloyte and decrease the mean age of erythrocyte, which can decrease $\mathrm{HbA}_{1 c}$ level. ${ }^{3}$ Since Vitamin B12 deficiency affects erythropoiesis and is itself cause of anemia it is likely that HbA1c level will be affected in Vitamin B12 deficiency anemia.

\section{Methods}

The study was conducted in tertiary care hospital Mahatma Gandhi Medical College and Hospital, Jaipur in the patients admitted in the medicine wards. It included 90 participants with 30 patients having iron deficiency anemia, 30 with Vitamin B12 deficiency anemia and rest 30 belong to the control group. All the patients were screened for Fasting Blood Sugar, Renal Function, Hematological parameters and those with Fasting Plasma Glucose $<100 \mathrm{mg} / \mathrm{dl}$ were classified into having iron deficiency anemia, vitamin B12 deficiency anemia and controls without anemia. HbA1c was measured in each group and as compared using ANOVA and T test analysis.

The data was recorded for all the eligible patients on a predesigned proforma and analyzed. The data will be presented as Mean \pm SD for continuous variables. A Student's t-test will be applied for comparison of group 
means. Pearson's coefficient of correlation will be calculated to determine the correlation between 2 variables. $P$ value of less than 0.05 will be considered statistically significant.

\section{Results}

During the period of study 90 patients were screened and out of which 30 were of iron deficiency anemia, 30 of vitamin B12 deficiency anemia and 30 were control. The mean age distribution of participants in Iron deficiency anemia was $36.27+7.282$, Vitamin B 12 deficiency group was $37.23+6.218$ and control group was $38.10+7.112$.

Out of 30 participants in each group, 11 participants (36.67\%) were male and 19 participants $(63.335 \%)$ were female in iron deficiency group, $16(53.33 \%)$ were male and $14(46.67 \%)$ were female in vitamin B12 deficiency group , 18 (60\%) were male and 12(40\%) were female in control group. The Mean $\mathrm{Hb}$ in Group 1(Iron deficiency Anemia) was 7.82+1.28, In Group 2 (Vitamin B 12 deficiency anemia) was 7.45+1.46, and in Group 3 (Control) 13.21+0.80. In Iron deficiency anemia 14 patients had moderate anemia and 16 patients had severe anemia. In Vitamin B 12 Deficiency group 9 patients belonged to moderate anemia and 21 patients belonged to severe anemia group.

Table 6: Mean S. Iron, Ferritin, Vitamin B12 levels in study group

\begin{tabular}{|c|c|c|c|c|c|c|c|c|c|}
\hline & \multirow{2}{*}{ Group } & \multirow{2}{*}{$\mathbf{N}$} & \multirow{2}{*}{ Mean } & \multirow{2}{*}{ SD } & \multicolumn{2}{|c|}{ ANOVA } & \multicolumn{3}{|c|}{ 'p' Value* } \\
\hline & & & & & $\mathbf{F}$ & 'p' Value & I-III & II-III & I-II \\
\hline \multirow{3}{*}{ Serum Iron $\mu \mathrm{gm} / \mathrm{dl}$} & I & 30 & 19.73 & 6.01 & \multirow{3}{*}{355.87} & \multirow{3}{*}{$<0.001$} & \multirow{3}{*}{$<0.001$} & \multirow{3}{*}{$<0.001$} & \multirow{3}{*}{$<0.001$} \\
\hline & II & 30 & 110.33 & 19.97 & & & & & \\
\hline & III & 30 & 81.24 & 10.33 & & & & & \\
\hline \multirow{3}{*}{$\begin{array}{c}\text { Serum ferritin } \\
\text { ng/ml }\end{array}$} & I & 30 & 7.28 & 1.90 & \multirow{3}{*}{117.509} & \multirow{3}{*}{$<0.001$} & \multirow{3}{*}{$<0.001$} & \multirow{3}{*}{$<0.001$} & \multirow{3}{*}{$<0.001$} \\
\hline & II & 30 & 72.03 & 26.54 & & & & & \\
\hline & III & 30 & 53.47 & 11.99 & & & & & \\
\hline \multirow{3}{*}{ Vitamin B $12 \mathrm{pg} / \mathrm{m}$} & I & 30 & 307.27 & 38.65 & \multirow{3}{*}{313.29} & \multirow{3}{*}{$<0.001$} & \multirow{3}{*}{0.760} & \multirow{3}{*}{$<0.001$} & \multirow{3}{*}{$<0.001$} \\
\hline & II & 30 & 78.07 & 13.33 & & & & & \\
\hline & III & 30 & 299.91 & 56.59 & & & & & \\
\hline
\end{tabular}

*Post hoc Tukey HSD

The Mean S. Iron levels in iron deficiency group was $19.73+6.01 \mu \mathrm{gm} / \mathrm{dl}, 110.33+19.97 \mu \mathrm{gm} / \mathrm{dl}$ in Vitamin B 12 deficiency group and $81.24+10.33 \mu \mathrm{gm} / \mathrm{dl}$ in control group. The mean serum ferritin levels in Iron deficiency group was $7.28+1.90 \mathrm{ng} / \mathrm{ml}, 72.03+26.54 \mathrm{ng} / \mathrm{ml}$ in Vitamin B12 deficiency group and 53.47+11.99 $\mathrm{ng} / \mathrm{ml}$ in control group. The mean serum vitamin B 12 levels in iron deficiency group was $307.27+38.65 \mathrm{pg} / \mathrm{ml}$, $78.07+13.33 \mathrm{pg} / \mathrm{ml}$ in vitamin B 12 deficiency group and $299.91+56.59 \mathrm{pg} / \mathrm{ml}$ in control group. the mean of fasting blood sugars in iron deficiency anemia was $84.33+5.93 \mathrm{mg} / \mathrm{dl}$, vitamin B12 deficiency anemia group was $88.83+6.69 \mathrm{mg} / \mathrm{dl}$ and control group was $84.07+6.99 \mathrm{mg} / \mathrm{dl}$.

The mean HbA1c levels in iron deficiency anemia group was 5.61+0.69, in Vitamin B12 deficiency was 5.50+0.39 and in control group was 5+0.32. The mean HBa1c value of both iron deficiency anemia and Vitamin B 12 deficiency anemia were more compared to control group and this difference was found to be statistically significant.

In Iron deficiency anemia 10 out of 30 participants $(33.33 \%)$ had $\mathrm{Hba}_{1 \mathrm{c}}$ in the range of impaired glucose homeostasis $(5.6-6.5)^{2}$ and in Vitamin B12 deficiency anemia 12 out of 30 participants $(40 \%)$ had $\mathrm{Hba}_{1 \mathrm{c}}$ in the range of impaired glucose homeostasis. Interestingly 2 patients from iron

Table 8: Mean $\mathrm{HbA}_{1 \mathrm{c}}$ levels of different groups

\begin{tabular}{|c|c|c|c|c|c|c|c|c|}
\hline Group & $\mathbf{N}$ & $\begin{array}{c}\text { Mean } \\
\text { HbA1c (\%) }\end{array}$ & SD & \multicolumn{2}{|c|}{ ANOVA } & \multicolumn{3}{|c|}{ 'p' Value* } \\
\cline { 5 - 8 } & & Hb & F & 'p' Value & I-III & II-III & I-II \\
\hline I & 30 & 5.61 & 0.69 & 13.00 & $<0.001$ & $<0.001$ & 0.001 & 0.665 \\
\hline II & 30 & 5.50 & 0.39 & & & & & \\
\hline III & 30 & 5.00 & 0.32 & & & & & \\
\hline
\end{tabular}

*Post hoc Tukey HSD

Deficiency anemia had $\mathrm{Hba}_{1 \mathrm{c}}$ in diabetic range (more then 6.5$)^{2}$. Our study reported significant negative trend when Hemoglobin was compared with $\mathrm{HbA}_{1 \mathrm{c}}$ in patients with iron deficiency anemia, that is, patients with lower Hemoglobin had higher $\mathrm{HbA}_{1 \mathrm{c}}$.

\section{Discussion}

Hemoglobin $A_{1 c}$ which has been included as a diagnostic tool for the diagnosis of Diabetes in American Diabetes Association criteria 2011 will now play an important role in diagnosis and treatment of Diabetes mellitus. ${ }^{4}$ However several factors other than blood sugar can alter the $\mathrm{HbA}_{1 \mathrm{c}}$ levels are blood loss $5^{5}$ hemolytic anemia ${ }^{6}$, blood urea, pregnancy ${ }^{7}$, Iron deficiency anemia and vitamin B 12 deficiency anemia.So 
we conducted a study to analyze the effects of iron deficiency anemia and Vitamin B12 deficiency anemia on $\mathrm{HbA}_{1 \mathrm{c}}$ levels.

We conducted a study on 60 patients of IDA and Vitamin B12 deficiency anemia along with 30 control to study the effect of anemia on $\mathrm{HbA}_{1 \mathrm{c}}$. Of 30 patients of IDA, 19 (63.33\%) were female and 11(36.67\%) were male. Among 30 patients of Vitamin B12 deficiency anemia, 14(46.67\%) were female and 16(53.33\%) were male. In the control group, 12 participants $(40 \%)$ were female and $18(60 \%)$ were male. This sample size was adequately matched with the studies conducted earlier. The mean age of the patients of IDA was $36.27 \mathrm{yr}$ and that of Vitamin B12 deficiency anemia was $37.23 \mathrm{yr}$. The mean age of the control participants was $38.10 \mathrm{yr}$. In Iron deficiency anemia 14 patients had moderate anemia and 16 patients had severe anemia. In Vitamin B 12 Deficiency group 9 patients belonged to moderate anemia and 21 patients belonged to severe anemia group. We found no cases of mild anemia.

Our results suggested that IDA was associated with higher concentrations of $\mathrm{HbA}_{1 \mathrm{c}}$. It was found that the mean values of $\mathrm{HbA}_{1 \mathrm{c}}$ in Iron deficiency group weresignificantly higher (5.61\%) compared to that of control group where it was $5.00 \%$. This difference was found to be significant $(\mathrm{P}<0.001$.) on statistical testing. Our study also revealed that the difference in mean $\mathrm{HbA}_{1 \mathrm{c}}$ levels of severely anemic patients $(6.04 \%)$ and moderately anemic patients $(5.11 \%)$ was statistically significant $(\mathrm{p}<0.001)$.

Although prolongation of erythrocyte survival in patients with IDA is known to elevate the $\mathrm{HbA}_{1 \mathrm{c}}$ level, some studies have shown normal or even shortened lifespans of erythrocytes in patients with IDA. In study by Sinha et al (2012) ${ }^{8}$ the $\mathrm{HbA}_{1 \mathrm{c}}$ levels were found to be significantly lower in patients with iron deficiency anemia than in the controls. Moreover, the $\mathrm{HbA}_{1 c}$ levels increased after treatment, which had not been reported in any previous study. The absolute $\mathrm{HbA}_{1 \mathrm{c}}$ levels, which were significantly lower in patients than in controls, were also found to increase significantly after iron treatment. The hemoglobin and $\mathrm{HbA}_{1 \mathrm{c}}$ levels were positively correlated in anemia patients before treatment, but no positive correlation was apparent at 2 months after treatment. The authors did not discuss why their data conflicts with other studies but Emma English et al. $(2015)^{9}$ in the review article postulated that it may be due to the severity of anemia as the participants in this study had low mean hemoglobin levels $(62 \mathrm{~g} / \mathrm{dl})$; the duration of anemia was not given. But in our study patients with severe anemia had significantly higher $\mathrm{HbA}_{1 \mathrm{c}}$ levels compared to patients with moderate anemia as well as controls.

The present study observed that 10 cases of Iron Deficiency Anemia and 12 cases of Vitamin B 12 deficiency anemia cases fell into impaired glucose homeostasiscategory and 2 patients of Iron Deficiency Anemia fell into diabetic category according to American Diabetes Association 2011 criteria even while their fasting sugars were normal. This agrees with Hardikar et al $(2012)^{10}$ who investigated a population where $34 \%$ were anemic, $37 \%$ were iron deficient, $40 \%$ were vitamin $\mathrm{B}_{12}$ deficient, and $22 \%$ were folate deficient. Only $20 \%$ of those diagnosed as prediabetic and diabetic by $\mathrm{HbA}_{\mathrm{lc}}$ had prediabetes and diabetes according to the OGTT, and among the anemic, this figure was only $7 \%$. In this young, apparently healthy, and non-diabetic group, 2-h glucose concentrations explained only $25.6 \%$ of the variance in $\mathrm{HbA}_{1 \mathrm{c}}$ concentrations and hematological parameters contributed up to $13.1 \%$, leaving over half of the variance unexplained. They concluded that use of $\mathrm{HbA}_{\mathrm{lc}}$ to diagnose prediabetes and diabetes in iron-deficient populations may lead to a spuriously exaggerated prevalence of prediabetes.

This study has got a significant relevance because Iron and Vitamin B12 deficiency anemia is very highly prevalent in a tropical country like India. Iron and Vitamin B12 deficiency anemia being common variables, influences the $\mathrm{HbA}_{1 \mathrm{c}}$ levels when they are estimated by the most commonly employed methods like immunoturbidometry and so, they must be corrected before making any diagnostic or therapeutic decision based on the $\mathrm{HbA}_{1 \mathrm{c}}$ levels. $\mathrm{HbA}_{1 \mathrm{c}}$ is commonly used to assess the long-term blood glucose control in the patients with diabetes mellitus, because the $\mathrm{HbA}_{1 c}$ value has been shown to predict the risk for the development of many of the chronic complications in diabetes.

\section{Bibliography}

[1]. Alvin C. Powers, Diabetes mellitus. Harrison's principles of internal medicine 18 ${ }^{\text {th }}$ ed. Mac Graw Hill. 2011;344:2968-80.

[2]. American diabetes association 2011 guidelines, Standards of Medical Care in diabetes-2011, Diabetes care. January 2011;34(supplement 1):S11-S14.

[3]. Gallagher EJ, Le Roith D, Bloomgarden Z. Review of hemoglobin A(1c) in the management of diabetes. J Diabetes. 2009;1:9-17.

[4]. American diabetes association 2011 guidelines, Standards of Medical Care in diabetes-2011, Diabetes care. January 2011; 34(supplement 1): S11-S14.

[5]. Bernstein RE. Glycosylated hemoglobins: hematologic considerations determine which assay for glycohemoglobin is advisable. Clinical Chemistry. 1980; 26:174-5.

[6]. Horton BF, Huisman TH. Studies on the heterogeneity of haemoglobin. VII. Minor haemoglobin components in haematological diseases. Br J Haematol 1965; 11:p296-304.

[7]. Hanson U, Hagenfeldt L, Hagenfeldt K. Glycosylated hemoglobins in normal pregnancy: sequential changes and relation to birth weight. Obstet Gynecol. 1983; 62:741-4.

[8]. Mayer TK, Freedman ZR. Protein glycosylation in diabetes mellitus: a review of the laboratory measurements and of their clinical utilities. Clin Chim Acta. 1983; 127:147e84. 
[9]. English E, Idris S, Smith G, Dhatariya K, Kilpatrick E, John W The effect of anaemia and abnormalities of erythrocyte indices on $\mathrm{HbA}_{\mathrm{lc}}$ analysis: a systematic review. Diabetologia. 2015; 58:1409-1421.

[10]. Hardikar PS, Joshi SM, Bhat DS, Raut DA, Katre PA, Lubree HG, Jere A, Pandit AN, Fall CH, Yajnik CS. Spuriously high prevalence of prediabetes diagnosed by $\mathrm{HbA}_{1 \mathrm{c}}$ in young Indians partly explained by hematological factors and iron deficiency anemia. Diabetes Care. 2012; 35:797-802. 